\title{
Use of 5-Fluorocytosine in Systemic Candidiasis in Infancy
}

\author{
M. ISACSON, Z. NOAH, J. FABER, Y. HERISHANO, and L. GOTTFRIED \\ From the Paediatric Gastroenterology Research Unit and Departments of Neurology and Clinical Pathology, Shaare \\ Zedek General Hospital, Jerusalem, Israel
}

\begin{abstract}
Isacson, M., Noah, Z., Faber, J., Herishano, Y., and Gottfried, L. (1972). Archives of Disease in Childhood, 47, 954 . Use of 5-fluorocytosine in systemic candidiasis in infancy. Three cases of systemic candidiasis were successfully treated with 5-fluorocytosine (5-FC), an antifungal agent. The fungaemia developed during continuous intravenous alimentation for intestinal malabsorption. The diagnosis was confirmed by repeated positive cultures from blood, urine, and faeces. The fungus was also grown from cultures of intravenous solutions and catheters. The clinical features varied and included unexplained fever, oedema, stupor, tachypnoea, convulsions, hepatosplenomegaly, and congestive heart failure. The clinical symptoms receded rapidly and the cultures became negative after oral or intravenous treatment with 5-FC.
\end{abstract}

The new methods of patient management in cases of gastrointestinal malabsorption may give rise to complications if they are used for a long period without proper preventive measures. The intravenous catheter, whether in a peripheral vein or in the superior vena cava, represents not only a foreign body but also a route by which contamination may occur. The intravenous solutions used, which are usually protein hydrolysates and glucose, may themselves provide a very good medium for candida growth (Cormane and Goslings, 1963; Groff, 1969). 5-Fluorocytosine, an antimetabolite of the pyrimidine base cytosine, has a high degree of activity against candida but has relatively little toxicity in man (Grunberg, Titsworth, and Bennett, 1963; Record et al., 1971; Davies and Reeves, 1971). It is not detectably metabolized and is mostly excreted unchanged in the urine.

We describe here 3 children who developed systemic candidiasis during continuous intravenous alimentation for intestinal malabsorption and who were treated successfully with 5-fluorocytosine.

\section{Case Report}

Case 1 was the first-born son of healthy Ashkenazi Jewish parents. Pregnancy and delivery were normal and the birthweight was $3950 \mathrm{~g}$. Complementary feeding with cow's milk began at the age of 1 week.

Received 11 April 1972.
Shortly thereafter, diarrheoa appeared insidiously and was treated with various antibiotics. As the diarrhoea persisted for 6 weeks, he was admitted to the Paediatric Gastroenterology Research Unit with a provisional diagnosis of cow's milk intolerance with secondary malabsorption. On admission in 7 June 1971 at the age of 2 months, he weighed $4200 \mathrm{~g}$, looked pale, grey, and wasted, and the anterior fontanelle was sunken. There was oral moniliasis. Laboratory investigations are noted in Table I. Esch. coli 0114 was isolated from his faeces, and, on the assumption that this infection was systemic as well as local, colistin was given orally and kanamycin systemically.

As malabsorption was suspected-and subsequently substantiated by the sugar tolerance tests-casein hydrolysate ('Amigen', Travenol Inc.), supplemented twice weekly by an infusion of blood or plasma, was given. In order to raise the caloric intake of the patient, a $50 \%$ glucose solution was added to the infusion bottle, to a final concentration of $10 \%$ glucose. Calcium, magnesium, and vitamins were given intramuscularly. This therapy was given continuously. As the diarrhoea continued even after oral feeding was stopped, a persistent infection was assumed. The emergence in the faeces of another strain of Esch. coli, O126, as well as Entamoeba histolytica necessitated the introduction of other antibiotics and di-iodohydroxquinolone. Thereafter, no further pathogenic organisms could be obtained from the stools but the infant's condition deteriorated. In the absence of any change in the daily fluid intake, the infant suddenly gained weight, and generalized oedema with hepatosplenomegaly appeared (see Table II), accompanied by spiky fever. Extensive 
TABLE I

Laboratory Findings During Systemic Candidiasis and Treatment With 5-FC

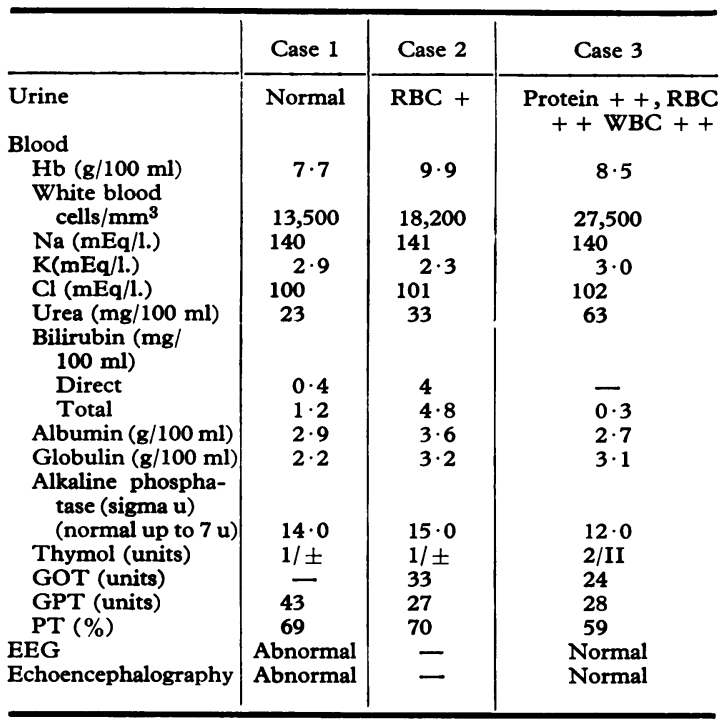

TABLE II

Clinical Findings During Systemic Candidiasis

\begin{tabular}{l|c|c|c}
\hline & Case 1 & Case 2 & Case 3 \\
\hline Spiky fever & + & + & + \\
Excessive weight gain & + & + & + \\
Tachycardia & + & + & + \\
Tachypnoea, dyspnoea & + & + & + \\
Jaundice & - & + & - \\
Hepatosplenomegaly & + & + & + \\
Heart murmur & - & + & - \\
Oedema & + & + & + \\
Diarrhoea & + & + & + \\
Seizures & + & - & + \\
\end{tabular}

investigations to ascertain the cause of the fever were negative. These included routine blood and urine cultures, Widal, Weil-Felix, and brucella antibodies, thick smear preparations for malaria, liver function tests, Mantoux test, subdural tap, screening of the diaphragm, $x$-rays of chest, abdomen, and skull, and IVP. Subsequently generalized convulsions appeared which were controlled by diazepam. An EEG showed medium amplitude slow waves in the right temporo-occipital region with a delta focus recorded from the same region. On the left side of the brain flat electrical activity was seen. The echoencephalogram showed a shift of the midline structures on the left (see Fig.). As sepsis was suspected, further antibiotics were given. At the end of July 1971 Candida tropicans was grown on blood culture. Blood obtained from different veins (in order to exclude a granuloma of the vein) as well as from urine and stools gave identical results (see Table III).
Treatment with oral 5-fluorocytosine (5-FC) was begun with an initial dosage of $100 \mathrm{mg} / \mathrm{kg}$ per day, rising later to $200 \mathrm{mg} / \mathrm{kg}$ per day. There was prompt cessation of fever and oedema, the liver and spleen returned to normal size, and the diarrhoea stopped. The general condition improved. Repeated EEG and echoencephalogram examinations showed progressive improvement with normalization of the recording after 8 weeks of treatment with 5-FC. The cessation of the diarrhoea enabled us to introduce slowly oral feedings of 'Nutramigen' (Mead Johnson) on which he gained weight rapidly and was discharged well in October 1971 weighing $5700 \mathrm{~g}$. Treatment with $5-\mathrm{FC}$ was continued for 12 weeks.

Case 2 was the first-born son of healthy Jewish parents of Sephardi origin. Pregnancy was normal and delivery was by the breech. The birthweight was $2400 \mathrm{~g}$. In spite of early respiratory distress, the infant could be discharged home at the age of 5 days. He was bottle fed and vomited 2 to 3 times daily. On a routine visit to an infant welfare clinic at the age of 1 month, central cyanosis, tachycardia, and rapid and laboured respirations were observed, and the abdomen was distended. These features had occurred several times previously but the parents had not appreciated their significance. The baby was referred to the regional hospital where methaemoglobinaemia was found on spectrophotometry. Cultures from blood, urine, CSF, and stool were negative, and chest and skull $x$-rays and ECG were normal. Intravenous fluids, antibiotics, and vitamin $C$ were administered and the cyanosis disappeared. On resumption of oral feeding, however, diarrhoea and vomiting recurred and oral thrush developed. The infant's condition deteriorated gradually. In the 8th week after admission, a programme of i.v. nutrition with 'Amigen' casein hydrolysate was instituted. On the assumption that the infant was intolerant of cow's milk, this was supplemented with oral feeding of $0.45 \%$ saline, $2.5 \%$ glucose, and $3 \%$ olive oil. Diarrhoea ceased gradually and the general condition and the infant's weight improved. Encouraged by this favourable turn of events, an oral soybean formula ('Hyprovit', Hayes Ltd., Ashdod) was introduced. Within a few hours, severe diarrhoea developed and the infant was transferred to the Paediatric Gastroenterology Research Unit at the Shaare Zedek Hospital in July 1971.

At this stage the infant was 3 months old and weighed $3100 \mathrm{~g}$. He was emaciated, pale, lying in opisthotonus, and crying weakly. The abdomen was distended. Laboratory investigations are noted in Table $\mathbf{I}$. Our regimen of intravenous therapy, as outlined in the first case report, was instituted and supplemented by oral glucose saline with olive oil. For the first 4 weeks his condition improved slowly but steadily, as judged by the disappearance of diarrhoea and vomiting and by weight gain. By this time, venepunctures became technically extremely difficult and puncture sites were frequently infected, despite local application of antibiotic ointment

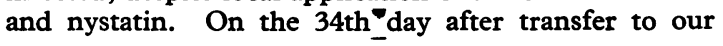


a

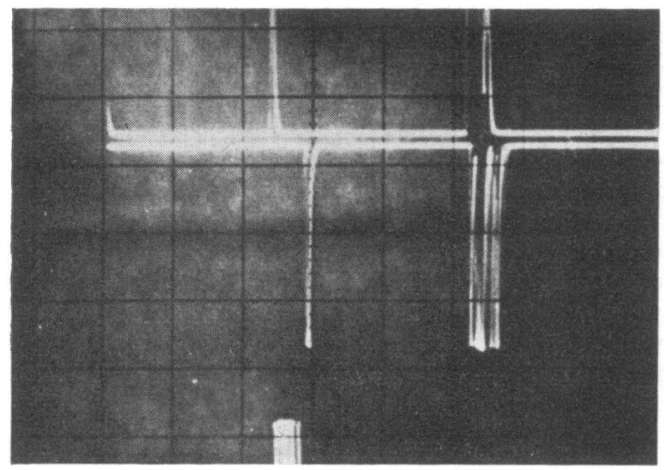

C

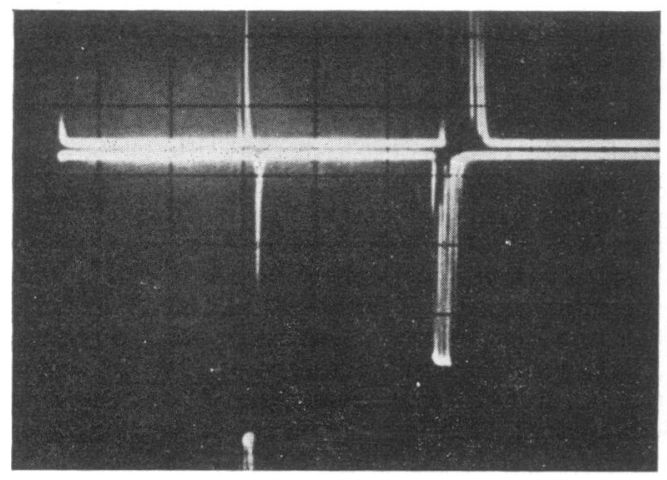

FIG.-Echoencephalogram of Case 1 (a) at 4 months, 5 months, 6 September 1971, and

unit a spiky fever developed. The infant was listless, grey, and the appetite was poor. The abdomen was distended and there was diffuse lymphadenopathy. A large abscess appeared in the right parietal region. Blood, urine, and stool cultures were taken and antibiotic therapy instituted. There was an initial response shown by subsidence of fever and swelling, but 2 days later fever recurred and was accompanied by jaundice, profuse diarrhoea, oedema, hepatosplenomegaly, and rapid respirations with intercostal recession (see Table II). A systolic murmur appeared. The results of cultures for candida are presented in Table III. Oral therapy with 5-FC was begun on the 48th day of hospitalization in a dosage of $150 \mathrm{mg} / \mathrm{kg}$ divided into 4 equal doses. 48 hours after initiation of therapy the fever settled, oedema lessened, and the liver and spleen receded. Therapy was continued for 3 months during which the infant was taken off intravenous fluids and given oral casein hydrolysate feedings.

Case 3. A male infant is the sixth child of healthy Arab parents. The parents are first cousins. He was born on 14 July 1971 after normal pregnancy and
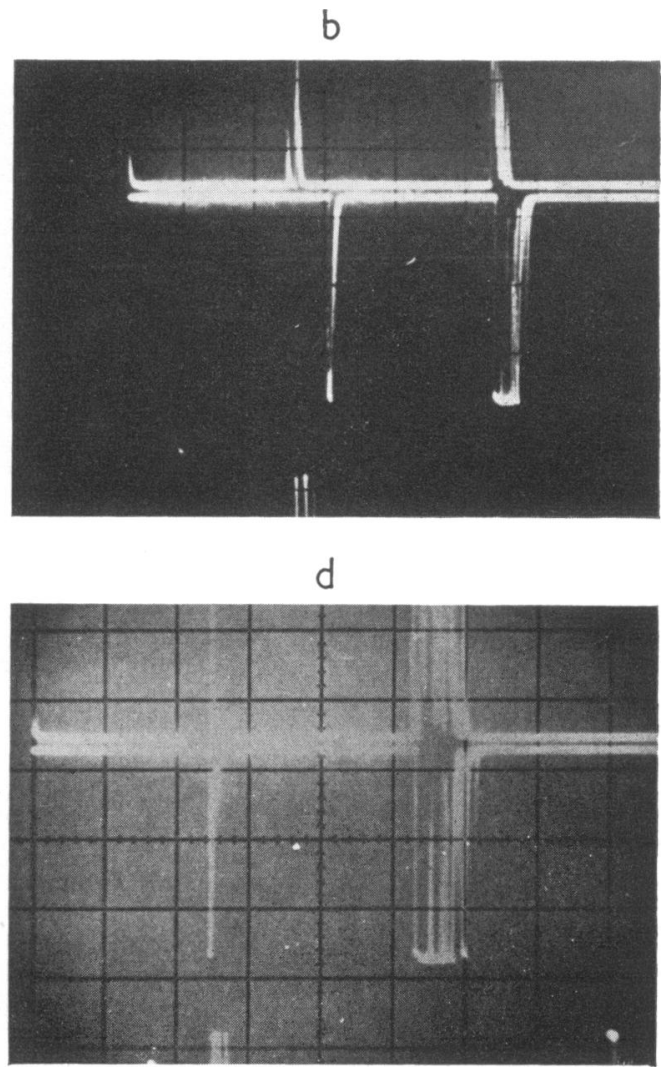

11 August 1971, (b) at 4 months, 16 August 1971, (c) at (d) at 6 months, 10 October 1971.

delivery. Birthweight was 4850 g.' From birth the infant was fed on cow's milk. According to the mother, fever appeared at the age of 4 days, ranging between $38^{\circ}$ and $39^{\circ} \mathrm{C}$, and remained raised. Antibiotic treatment was given. The mother claimed that in spite of the fever the boy appeared well, ate well, and was in a good mood. As fever did not subside, he was admitted for investigations to our department on 14 September 1971 at the age of 2 months.

On admission he weighed $3890 \mathrm{~g}$, and temperature was $37 \cdot 6^{\circ} \mathrm{C}$. The patient looked very dehydrated. Seborrhoeic dermatitis was apparent on most of his body. No other pathological findings were found on physical examination. Diarrhoea was present on admission and the baby's condition suggested that it had been present for some time. A glucose oxidase test of stools was positive for glucose with oral feeding on cow's milk. Malabsorption was assumed to be present and feeding was changed to 'Nutramigen'. Repeated stool cultures for pathogens were negative. As diarrhoea did not subside, intravenous alimentation was started with a casein hydrolysate as in Case 1. Electrolytes and vitamins were added parenterally. 
TABLE III

Microbiological Results

\begin{tabular}{|c|c|c|c|c|c|c|c|c|c|c|c|}
\hline & & \multicolumn{7}{|c|}{ Sources of Positive Cultures } & \multicolumn{2}{|c|}{$\begin{array}{c}\text { Negative } \\
\text { Results }\end{array}$} & \multirow{2}{*}{$\begin{array}{c}\text { Indirect } \\
\text { HA } \\
\text { Titrest }\end{array}$} \\
\hline & & MIC & Blood & Urine & Faeces & $\begin{array}{c}\text { I.V. } \\
\text { Solutions }\end{array}$ & $\begin{array}{l}\text { I.V. } \\
\text { Set }\end{array}$ & $\begin{array}{c}\text { Skin } \\
\text { Wound }\end{array}$ & Blood & Urine & \\
\hline $\begin{array}{l}\text { Case } 1 \\
\text { Before treatment } \\
\text { with 5-FC } \\
\text { During treatment } \\
\text { After treatment }\end{array}$ & $\begin{array}{l}\text { Candida albicans } \\
\text { Candida tropicalis } \\
\text { Candida albicans } \\
\text { Candida albicans }\end{array}$ & $\begin{array}{l}0 \cdot 4 \\
3 \cdot 2 \\
0 \cdot 4\end{array}$ & $\begin{array}{l}2 \ddagger \\
3 \\
1\end{array}$ & $\begin{array}{l}1 \\
1\end{array}$ & & & & & $\begin{array}{l}3 \\
4\end{array}$ & $\begin{array}{l}2 \\
2\end{array}$ & $\begin{array}{l}1 / 20 \\
1 / 40 \\
1 / 10\end{array}$ \\
\hline $\begin{array}{l}\text { Case } 2 \\
\text { Before treatment } \\
\text { with 5-FC } \\
\text { During treatment } \\
\text { After treatment }\end{array}$ & $\begin{array}{l}\text { Candida albicans } \\
\text { Candida albicans } \\
\text { Candida albicans }\end{array}$ & 0.4 & 4 & 1 & & 1 & 1 & 1 & $\begin{array}{l}2 \\
2\end{array}$ & $\begin{array}{l}4 \\
2\end{array}$ & $\begin{array}{l}1 / 80 \\
1 / 160 \\
1 / 40\end{array}$ \\
\hline $\begin{array}{l}\text { Case } 3 \\
\text { Before treatment } \\
\text { with 5-FC } \\
\text { During treatment } \\
\text { After treatment }\end{array}$ & $\begin{array}{l}\text { Candida albicans } \\
\text { Candida albicans } \\
\text { Candida albicans }\end{array}$ & 0.4 & $\begin{array}{l}6 \\
2\end{array}$ & $\begin{array}{l}2 \\
2\end{array}$ & 1 & 2 & & & 4 & 2 & $\begin{array}{l}1 / 10 \\
1 / 80\end{array}$ \\
\hline
\end{tabular}

^Minimal inhibitory concentration (mg of 5-FC/ml) performed by Hoffman La Roche, Basle, Switzerland.

†Haemagglutinin titre to candida, performed by Hoffman La Roche, Basle, Switzerland.

$\ddagger$ Numbers of cultures performed.

Blood or plasma was added once or twice weekly as a supply of trace elements and to repair anaemia. Antibiotics were not given.

After 36 days of hospitalization, while the patient was improving gradually, we were alerted by the appearance of spiky fever, accompanied by excessive weight gain, oedema, and hepatosplenomegaly. Tachycardia as well as bouts of tachypnoea alternating with apnoea appeared. The child looked ashen-grey, stuporose, and had a constant tremor of the upper limbs. Two days later he had a series of convulsions in the course of 2 days. EEG and echoencephalogram were normal. On blood and urine cultures Candida albicans was isolated (Table III).

Because of the rapid deterioration, 5-FC was started intravenously in a dosage of $100 \mathrm{mg} / \mathrm{kg}$ per day. Later, as clinical improvement appeared, it was given orally. In addition, the patient received a course of cephaloridine parenterally, $270 \mathrm{mg} / \mathrm{kg}$ per day for 10 days. His condition improved promptly and within 10 days all the above-mentioned acute symptoms cleared and consciousness returned. Diarrhoea continued. Treatment with 5-FC was continued for 60 days. He was discharged after 107 days in hospital, weighing $4710 \mathrm{~g}$ and eating a full diet.? $1,2,5.5 / 12=75 \%$

\section{Discussion}

The diagnosis of systemic candidiasis must be based on (1) positive cultures for candida, (2) suspicious clinical features, (3) the presence of predisposing factors, and (4) a good response to specific antifungal treatment given early in the disease.
Due to its ubiquity, the recovery of candida from sputum, stool, vagina, or even umbilical stump may have no significance (Toala et al., 1970). Even candida in the blood-stream or urine may represent a transient contamination which the body can overcome without the aid of drugs (Ellis and Spivack, 1967). Occasionally, fungaemia may occur before death without clinical evidence of disseminated candidiasis. Candiduria can also be a transient phenomenon, but, if persistent, may represent an indicator of disseminated candidiasis (Ellis and Spivack, 1967).

When candida has been repeatedly isolated from blood and urine in the presence of symptoms compatible with systemic fungal infection, this diagnosis must be seriously considered. Though no typical features of disseminated candidiasis have been described, the 3 cases reported here showed a number of features common to all (see Table II).

The predominant symptoms in our first case were fever, oedema, hepatomegaly, together with clinical EEG and echoencephalographic evidence of an intracranial space-occupying lesion (see Fig. 1). After treatment there was a regression of the systemic as well as the neurological signs. The return to normal of the EEG and echoencephalograms after the institution of antifungal therapy would be consistent with the diagnosis of candida granuloma in the right cerebral hemisphere. 
In our second case the predominant clinical features, in addition to fever, stupor, and tachypnoea, were congestive heart failure with hepatosplenomegaly and oedema. The congestive heart failure was considered to be due to cardiac involvement by the infecting fungus, as the clinical signs improved on antifungal therapy.

The third case had spiky fever, tachypnoea alternating with apnoea, hepatosplenomegaly, unexplained excessive weight gain, stupor, and convulsions. In this case EEG and echoencephalograms were normal.

Although Skobel, Schabinski, and Essigke (1956) found that $9 \%$ of healthy babies under 3 months of age had antibodies to candida, it is possible that rising anticandida titres, as were seen in all our patients, may have a diagnostic value (Müller, 1967). The low titre of anticandida antibodies and their rapid decrease after treatment may also reflect the effectiveness of 5-FC on these short-lived infections. Murray, Buckley, and Turner (1969) thought that precipitins to candida in a relatively high titre may be helpful in the diagnosis of systemic candidiasis, while Pepys et al. (1968) noted that precipitins against protein antigens of candida albicans are relatively common in asthmatic patients without clinical evidence of candidiasis.

The incidence of severe systemic candidiasis is increasing as a result of modern medical therapy, such as the use of broad-spectrum antibiotics, immunosuppressive drugs, or the use of intravenous catheters for prolonged intravenous alimentation.

The observations of Cormane and Goslings (1963) and Boeckman and Krill (1970) suggested that solutions of amino acids and glucose may be particularly favourable media for the growth of candida, the richness of growth being proportional to the concentration of glucose.

Despite the difficulties and dangers in its use, amphotericin-B is still widely used in disseminated candidiasis. In a search for new antifungal agents less toxic than amphotericin-B, 5-FC, among others, was found to be effective against systemic candidiasis as well as against other fungal infections (Grunberg et al., 1963; Scholer, 1970; Davies and Reeves, 1971). 5-Fluorocytosine $\left(\mathrm{RO}_{2} 9915 / \mathrm{B}_{1}\right)$, an antimetabolite of the pyrimidine base cytosine, shows a high degree of activity against candida species, especially Candida albicans. It is not detectably metabolized and is mostly excreted in the urine in an unchanged form. The drug was shown to have a pronounced effect on intravenously administered candida infection in mice, and there have been reports of its successful use in fungal infection in man. The minimum inhibitory concentration of
5-FC reported for candida species ranged from 0.23 to $3.9 \mathrm{mg} / \mathrm{ml}$ (Shadomy, 1969).

To the best of our knowledge, this is the first trial of 5-FC for systemic candidiasis in infants. Furthermore, the intravenous administration of the drug, as given in our third case, has not been previously described. In this patient the intravenous administration of the drug enabled us to overcome possibly insufficient assimilation due to the patient's malabsorption syndrome. Even with oral therapy, however, a sufficient amount of the drug was obviously absorbed in the other two cases, resulting in cure without the need for discontinuing intravenous alimentation.

Apart from prompt improvement in the general condition and rapid disappearance of clinical features, the second and third cultures taken after the institution of therapy with 5-FC in our first and third cases, respectively, were negative and remained so subsequently. The treatment was continued at a dosage of $200 \mathrm{mg} / \mathrm{kg}$ per day for periods up to 12 weeks. Sensitivity studies should always be undertaken before and during therapy with 5-FC since there are reports of resistance to 5-FC in isolates of Candida albicans from patients receiving the drug (Shadomy, 1969).

By meticulous care it should be possible to prevent candida superinfection in patients receiving prolonged intravenous nutrition. Numerous reports of this complication, however, show that this ideal is not easily achieved (Groff, 1969; Record et al., 1971; Boeckman and Krill, 1970). The advantage of effective antifungal therapy must not take the place of prophylactic measures such as the use of local application of antiseptic and antimycotic solutions to the puncture site, daily changing of the infusion set, and the use of a millipore filter between the patient and the infusion bottle.

We wish to thank Hoffman La Roche, Basle, Switzerland, for a supply of 5-fluorocytosine and for performing microbiological tests.

REFERENCES

Boeckman, C. R., and Krill, C. E. Gr. (1970). Bacterial and fungal infections complicating parenteral alimentation in infants and children. Fournal of Pediatric Surgerv, 5, 117.

Cormane, R. G., and Goslings, W. R. D. (1963). Factors influencing the growth of candida albicans. Sabouraudia, 3, 52.

Davies, R. R., and Reeves, D. S. (1971). 5-fluorocytosine and urinary candidiasis. British Medical fournal, 1, 577.

Ellis, C. A., and Spivack, M. L. (1967). The significance of candidemia. Annals of Internal Medicine, 67, 511.

Groff, D. B. (1969). Complications of intravenous hyperalimentation in newborns and infants. Fournal of Pediatric Surgery, 4, 460.

Grunberg, E., Titsworth, E., and Bennett, M. (1963). Chemotherapeutic activity of 5 -fluorocytosine. In Antimicrob Agents Chemother, p. 566. University of Michigan Press, Ann Arbor. 
Müller H. L. (1967). Der Hămagglutinationstest in der CandidaSerologie, Sonderdruck aus Krankheiten durch Aktinomyzeten und verwandte Erreger Wechselwirkung zwischen pathogenen Pilzen und Wirtsorganismus. Springer, Berlin.

Murray, I. G., Buckley, H. R., and Turner, G. C. (1969). Serological evidence of candida infection after open heart surgery. Fournal of Medical Microbiology, 2, 463.

Pepys, J., Faux, J. A., Longbottom, J. L., McCarthy, D. S., and Hargreave, F. E. (1968). Candida albicans precipitins in respiratory disease in man. Fournal of Allergy, 41, 305.

Record, C. O., Skinner, J. M., Sleight, P., and Speller, D. C. E. (1971). Candida endocarditis treated with 5-fluorocytosine. British Medical fournal, 1, 262.

Scholer, H. J. (1970). Antimykoticum 5-fluorocytosin (oral antimycotic agent, 5-fluorocytosine). Mykosen, 13, 178
Shadomy, S, (1969), In vitro studies with 5-fluorocytosine. Applied Microbiology, 17, 871.

Skobel, P., Schabinski, G., and Essigke, G. (1956). Untersuchungen ueber die Immunitaetslage und den Wert der Serodiagnostik bei Candida-Mykosen. Arztliche Wochenschrift, 11, 317

Toala, P., Schroeder, A. S., Daly, A. K., and Finland, M. (1970). Candida at Boston City Hospital. Archives of Internal Medicine, 126, 983.

Correspondence to Dr. M. Isacson, Department of Paediatrics, Shaare Zedek General Hospital, P.O. Box 293, Jerusalem, Israel. 